\title{
Heller syndrome in two Iraqi children
}

\author{
Aamir Jalal Al Mosawi ${ }^{1,2 *}$ \\ ${ }^{1}$ Advisor in Pediatrics and Pediatric Psychiatry, Children Teaching Hospital of Baghdad Medical City, Iraq \\ ${ }^{2} \mathrm{Head}$, Iraq Headquarter of Copernicus Scientists International Panel, Baghdad, Iraq
}

\begin{abstract}
Heller syndrome is a rare heterogeneous clinical syndrome that is distinctive from autism and Asperger syndrome. It is characterized by a significant developmental regression resulting in deterioration in behavioral and adaptive functioning including self-help skills with loss of language and social skills after a period of normal development for at least two years.

The condition was first reported in 1908 by Theodor Heller in his paper "Über Dementia Infantilis". He called the condition "Dementia infantilis". During the previous few decades, Heller syndrome has been increasingly known as "Childhood disintegrative disorder" which was included in the fourth edition of the Diagnostic and Statistical Manual of Mental Disorders, or DSM-IV in 1994 as one of the pervasive developmental disorders.

Several authors have emphasized the rarity of the disorder. However, the disorder has been reported in several countries including Austria, United Kingdom, United States of America, Japan, India, Canada, Denmark, Spain, Thailand, and France.

We have previously observed Heller syndrome in Iraqi patients, however, the syndrome has not been well documented or reported from Iraq in the medical literature.

The main aim of this paper is to describe two Iraqi children with Heller syndrome, one of them have changes on brain MRI suggestive of cerebral vasculitis.
\end{abstract}

\section{Introduction}

Heller syndrome is a rare heterogeneous clinical syndrome that is distinctive from autism and Asperger syndrome. It is characterized by a significant developmental regression resulting in deterioration in behavioral and adaptive functioning including self-help skills with loss of language and social skills after a period of normal development for at least two years. The condition was first reported in 1908 by Theodor Heller in his paper "Über Dementia Infantilis". He called the condition "Dementia infantilis" [1-5].

During the previous few decades, Heller syndrome has been increasingly known as "Childhood disintegrative disorder" which was included in the fourth edition of the Diagnostic and Statistical Manual of Mental Disorders, or DSM-IV in 1994 as one of the pervasive developmental disorders. The term pervasive developmental disorders was probably first used during the 1980s. Pervasive developmental disorders include five chronic disorders marked by early impairment in socialization, communication, and behavior [6-9].

These disorders were first recognized by Grunya Efimovna Sukhareva in 1925, a Soviet pediatric psychiatrist who called these disorders autistic psychopathy [1-3].

In general, most of manifestations of pervasive developmental disorders result from impairments in social interaction and communication and behavioral problems [1-3].

\section{General manifestation of pervasive developmental disorders} include

- Difficulties in using and understanding language.

- Impaired social interaction marked by lack of eye contact, lack of facial responses and not responding to own name appropriately.
- Unusual patterns of playing with toys and other objects that can be marked by restricted interests.

- Repetitive body movements or behavior patterns including hand flapping, hair twirling, foot tapping, spinning, or other complex movements [1-5].

The American Psychiatric Association Diagnostic and Statistical Manual of Mental Disorders (DSM-IV,1994) divides pervasive developmental disorders five subgroups

- Autistic disorder.

- Asperger syndrome

- Rett's disorder

- Childhood disintegrative disorder (Heller syndrome).

- Pervasive developmental disorder not otherwise specified $[3,9]$.

Regressive autism is just like Heller syndrome, it is associated with initial normal development followed by loss of the previously acquired skills of socializing, communication, and language skills. However, regressive autism is not associated with features of dementia or significant mental retardation [1-3].

${ }^{*}$ Correspondence to: Aamir Jalal Al Mosawi, Advisor in Pediatrics and Pediatric Psychiatry, Children Teaching Hospital of Baghdad Medical City, Iraq, E-mail: almosawiAJ@yahoo.com

Key words: Heller syndrome, Iraq, brain MRI, cerebral vasculitis

Received: August 15, 2019; Accepted: August 23, 2019; Published: August 26 2019 
Pervasive developmental disorders has recently been called autism spectrum disorder mostly by the American Psychiatric Association, and the term pervasive developmental disorders has been used with the term autism spectrum disorder interchangeably $[2,3,9]$.

We have previously observed Heller syndrome in Iraqi patients, however, the syndrome has not been well documented or reported from Iraq in the medical literature. The main aim of this paper is to describe two Iraqi children with Heller syndrome, one of them have changes on brain MRI suggestive of cerebral vasculitis.

\section{Case Report}

The first patient was born on the $18^{\text {th }}$ of August, 2014 and was first seen at the age of four years and ten months (His weight was 18 kilograms). He was the product of a consanguineous marriage, and he was one of twins. He was considered normal until shortly after the age of two and half years when the family thought that he was gradually becoming stupid with gradual deterioration of social interaction. Thereafter, he experienced loss of adaptive self-care skills with loss of bowel control and the development of repetitive behaviors. His early development was considered better than his twin sister, and the family was sure that he started speaking before his twin sister.

At the clinic (Figure 1), the boy was not saying any word, but he was responding to his name and had some eye contact, but he was not communicating or responding to any question or request. He showed marked repetitive behaviors.

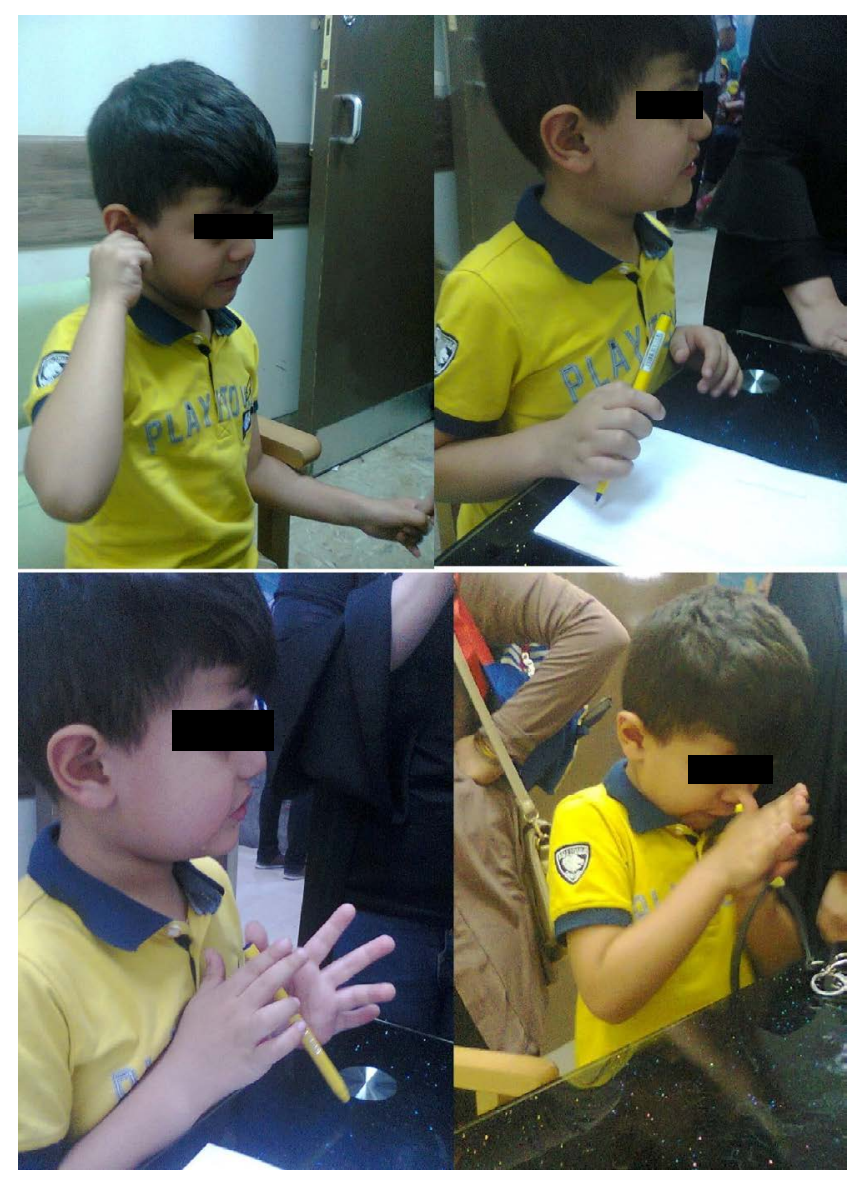

Figure 1. At the clinic, the boy showed minimal eye contact, and was not communicating or responding to any question or request, and showed marked repetitive movements
Electroencephalography and brain CT-scanning didn't show obvious abnormality.

\section{The boy was initially treated with:}

Intramuscular cerebrolysin $5 \mathrm{ml}$ daily for 10 days, followed by 10 injection given on alternate days. Oral prochloperazine $1 \mathrm{~m}$ at night.

The family reported some improvement in many aspects of his illness including speech after one month of treatment.

The second patient was first seen on the $30^{\text {th }}$ of June, 2019. The child's development was considered normal by the age of four years, and his illness started insidiously with:

- Gradual deterioration in speech and cognition.

- Development of abnormal behaviors including motor stereotypies.

- Loss of communication and social skills.

- Deterioration in adaptive self-care skills including bowel and bladder control, eating, dressing and undressing.

Within several months, the boy reached a state of overtly bizarre behavior and dementia, and was saying nothing. His motor functions remained good and enabled him to do things like bizarre dancing. $\mathrm{He}$ didn't develop abnormal movements suggesting seizure nor chorea, and he didn't have ataxia, but he was sometimes deliberately walk on his toe, an abnormality that was corrected by a yell from his father. There was no history of significant fever, headache, or impaired consciousness. Family history was negative.

Early pediatric Huntington disease and subacute sclerosing panencephalitis were considered but were mostly unlikely diagnoses. Although the child was responding to name most of the time and had rather acceptable eye contact most of the time, clinically his illness went more with a diagnosis of Heller dementia.

This case demonstrate a strange failure in seeking the appropriate consultant and a strange failure of making appropriate referral by doctors.

When the child aged seven years the parents consulted a practitioner of internal medicine A.M.A, who referred the patient to the private clinic of a very old retired neurosurgeon S.W who himself had Parkinson disease, and the practitioner wrote in his referral message "The patient was seen by many doctors with no response for your kind management.

At the clinic (Figure 2), the boy showed marked repetitive movements, and was rather uncontrollable and tried to move from place to place in the room.

Brain CT-scan performed during November,2014 showed normal findings.

Electroencephalography performed on the $20^{\text {th }}$ of January 2016 showed didn't show any epileptiform discharges, paroxysmal activity or focal abnormality.

On the first of November,2016, brain MRI showed single small right parietal hyperintense signal suggesting vasculitis.

Before referral, may tests were performed including tests for Wilson disease and lead poisoning, and all were negative.

On February, 13, 2019, a large number of immunologic screening tests were performed, and all were negative. 


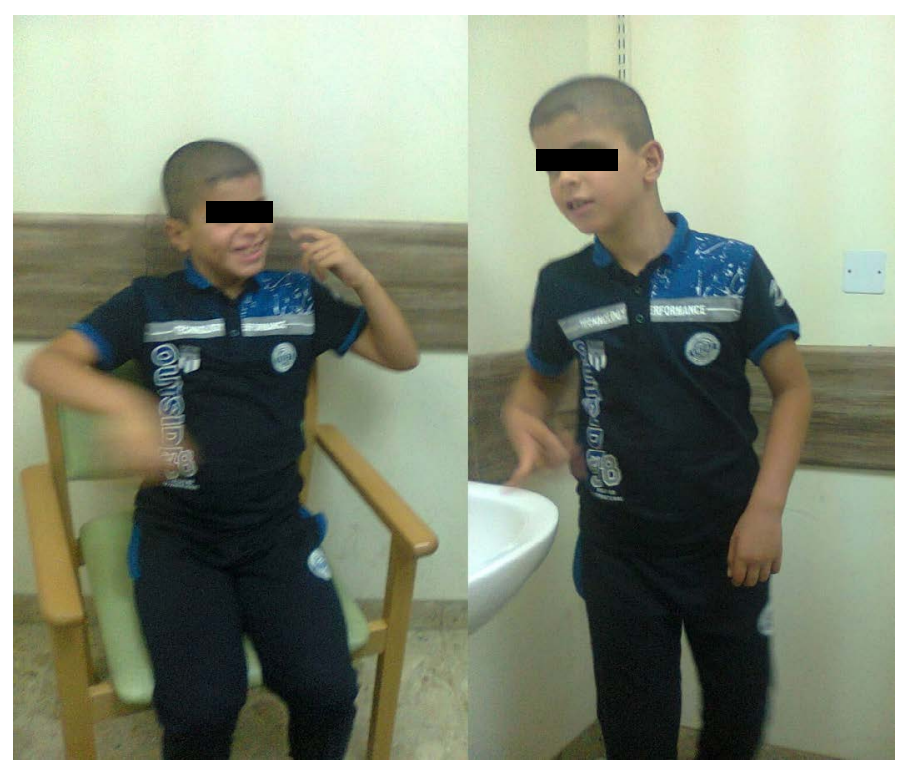

Figure 2. At the clinic, the second patient showed was rather uncontrollable tried to move from place to place in the room

Treatment was based on our published experience with the treatment of pervasive developmental disorders [1,5,10-12].

\section{During the first 10 days treatment included:}

- Oral trifluoperazine $1 \mathrm{mg}$ at night.

- Oral prochloperazine $5 \mathrm{mg}$ daily in the afternoon.

- Oral citicoline $2 \mathrm{ml}(200 \mathrm{mg})$ in the morning.

- Intramuscular cerebrolysin $5 \mathrm{ml}$ daily in the morning.

\section{During the second 10 days treatment included:}

- Oral trifluoperazine $1 \mathrm{mg}$ in the morning.

- Oral prochloperazine $5 \mathrm{mg}$ daily in the afternoon.

- Oral resperidon $1 \mathrm{mg}$ at night.

- Oral citicoline $2 \mathrm{ml}(200 \mathrm{mg})$ in the morning.

- Intramuscular piracetam 1 gram daily in the morning.

Treatment was associated with slight improvement with hardly noticeable improvement in speech and social interaction, but he was accepting to shake hand with doctor after treatment.

\section{Discussion}

We have previously observed Heller syndrome in Iraqi patients, however, the syndrome has not been well documented or reported from Iraq in the medical literature.

Although, the underlying etiologic factors in most cases of Heller syndrome, several reported cases were associated with a possible etiologic factor such as chronic encephalitis, cortical dysrhythmia, cerebral atrophy, reduction of brain volume, anti-NMDA-receptor encephalitis, vitamin B12 deficiency and hyperhomocysteinemia, chicken pox [4].
Several authors have emphasized the rarity of the disorder including Fombone, Burd and colleagues, Charan, Malhotra, et al. and Tapanadechopone who reported the first patient in Thailand $[4,10]$.

However, the disorder has been reported in several countries including Austria, United Kingdom, United States of America, Japan, India, Canada, Denmark, Spain, Thailand, and France [4].

Fombone from Canada studied 32 epidemiological surveys of autism and pervasive developmental disorders published in English language journals since 1966 were reviewed [10].

Four surveys estimated a prevalence of Heller syndrome ranging from 1.1 to 6.4 per 100,000 individuals. A pooled estimate across these four surveys is 1.7 per 100,000 (95 percent Confidence Interval: 0.6-3.8 per 100,000).

The study of Fombone suggested that Heller syndrome is very rare condition and its prevalence is 60 times less than that for autistic disorder, supposing a prevalence of 10 per 10,000 for autism.

According to Fombone, if the rate of all pervasive developmental disorders is 30 per 10,000 , there will be one child with Heller syndrome of 175 children with a diagnosis of a pervasive developmental disorder [10].

The two reported Iraqi patients with Heller syndrome demonstrated the heterogeneous nature of this clinical syndrome.

\section{Acknowledgement}

The author would to express his gratitude for the parents of the patients who accepted publishing his photos.

\section{References}

1. Al-Mosawi AJ (2019) The pattern of pervasive developmental disorders in Iraqi children. (1st Edn) Saarbrücken; LAP Lambert Academic Publishing.

2. Al-Mosawi AJ (2018) Asperger syndrome and regressive autism. (1st Edn) Saarbrücken; LAP Lambert Academic Publishing.

3. Al-Mosawi AJ (2018) Pediatric psychiatry: An accredited training course. (1st Edn) Saarbrücken; LAP Lambert Academic Publishing.

4. Al-Mosawi AJ (2019) Childhood dementia: Heller syndrome. (1st Edn) Saarbrücken LAP Lambert Academic Publishing.

5. Al-Mosawi AJ (2019) New therapies for Rett syndrome. J Bio Innov 8: 301-307.

6. Corbett J, Harris R (1977) Progressive disintegrative psychosis of childhood. J Child Psychol Psychiatry 18: 211-219.

7. Volkmar FR, Rutter M (1995) Childhood disintegrative disorder: results of the DSMIV autism field trial. J Am Acad Child Adolesc Psychiatry 34: 1092-1095.

8. Hendry CN (2000) Childhood disintegrative disorder: should it be considered a distinct diagnosis? Clin Psychol Rev 20: 77-90.

9. Diagnostic and Statistical Manual of Mental Disorders (1995) (4th Edn) American Psychiatric Association, Washington DC.

10. Fombone E (2002) Prevalence of childhood disintegrative disorder. Autism 6: 149-157.

11. Al-Mosawi AJ (2019) The use of cerebrolysin and citicoline in autism and Asperger syndrome. J Bio Innov 8: 99-108.

12. Al-Mosawi AJ (2018) A new therapeutic approach for pervasive developmental disorders. (1st Edn) Saarbrücken; LAP Lambert Academic Publishing.

Copyright: (C2019 Mosawi AJA. This is an open-access article distributed under the terms of the Creative Commons Attribution License, which permits unrestricted use, distribution, and reproduction in any medium, provided the original author and source are credited. 